\title{
Effect of Bleaching Agents on the Sealing of Cervical Barrier in Intracoronal Bleaching Procedures
}

\author{
Karen Cristina Kazue Yui, Maria Filomena Rocha Lima Huhtala, Eduardo Galera da Silva, Carolina Judica Ramos, \\ Carlos Rocha Gomes Torres, Sérgio Eduardo de Paiva Gonçalves, Ana Paula Martins Gomes
}

\begin{abstract}
Discoloration of nonvital teeth is an esthetic deficiency frequently requiring bleaching treatment. The purpose of this study was to evaluate in vitro the effect of bleaching agents on two different cervical barriers in order to minimize or prevent the leakage along the root canal filling in the intracoronal bleaching procedures. Ninety-six extracted human molars were used which were biomechanically prepared, filled and divided into eight groups. The cervical barriers tested were zinc phosphate cement (ZPC) and resin-modified glass ionomer cement (RMGIC) applied (3 $\mathrm{mm}$ of thickness) at the cementoenamel junction level. Forty-eight specimens were divided into four groups for each cervical barrier: (1) control group without bleaching agent, (2) a mixture of sodium perborate and distilled water, (3) a mixture of sodium perborate and $10 \%$ carbamide peroxide and (4) a mixture of sodium perborate and $35 \%$ carbamide peroxide. The bleaching agents were placed inside the pulp chamber for 7 and 14 days, and the access opening was sealed with Cimpat. After 21 days, microleakage evaluation of $2 \%$ rhodamine $B$ dye solution at dentin-cervical barrier interface was performed by a stereomicroscope. Data were submitted to Kruskal-Wallis, Dunn's and Dunnett's tests, with a significance level of 0.05 . The results demonstrated no statistically significant differences among the control group and the experimental groups for each cervical barrier (ZPC and RMGIC); there were no significant differences among the bleaching agents for the same barrier and RMGIC barrier provided better sealing than ZPC $(p<$ $0.05)$. Therefore, the bleaching agents demonstrated similar performance when tested for the same cervical barrier and RMGIC barrier provided better sealing than the ZPC barrier, regardless of the association of bleaching agents used.
\end{abstract}

Keywords: Tooth bleaching, Intracoronal bleaching, Sodium perborate, Carbamide peroxide.

How to cite this article: Yui KCK, Huhtala MFRL, da Silva EG, Ramos CJ, Torres CRG, de Paiva Gonçalves SE, Gomes APM. Effect of Bleaching Agents on the Sealing of Cervical Barrier in Intracoronal Bleaching Procedures. World J Dent 2013;4(4): 235-240.

\section{Source of support: Nil}

Conflict of interest: None declared

\section{INTRODUCTION}

Dental bleaching has been used worldwide for over a century and the search for white and perfect teeth has increased. The development of new bleaching and restorative materials, as well as the techniques evolution, has lead dentist to fulfill patients esthetic needs.

The hesitation of dentists about the use of bleaching agents is the occurrence of external cervical root resorption which has been associated with $30 \%$ hydrogen peroxide for intracoronal bleaching or 'walking bleaching technique'., The etiology of the resorption is still unknown, although some hypotheses have been proposed to explain it.

The association of sodium perborate and water for the intracoronal bleaching has been proved to be as efficient as the mixture of sodium perborate with hydrogen peroxide and it has been recommended to prevent or minimize the occurrence of external cervical root resorption. ${ }^{3-7}$ Another material that could be clinically used for the intracoronal bleaching technique is the $10 \%$ carbamide peroxide ${ }^{8,9}$ even though this material was less effective than $30 \% \mathrm{H}_{2} \mathrm{O}_{2}$ mixed with sodium perborate. ${ }^{8}$ The $10 \%$ carbamide peroxide is an effective bleaching agent that provides esthetic results comparable to the combination of sodium perborate and water. Although it has been proven to be safe and effective as a vital bleaching agent, carbamide peroxide needs to be evaluated to determine any association with external cervical root resorption. ${ }^{9}$

Some authors suggest that root canal obturation should be protected with a base prior to internal bleaching, in order to prevent the penetration of bleaching agents in apical direction $^{5}$ and to protect the dentin tubules that are situated near the gingival insertion, ${ }^{10}$ since there were cases of resorption in teeth that did not use cervical barrier before intracoronal bleaching procedures. ${ }^{2,11}$

Considering the fact that there are questions about the thickness and type of material that should be used as cervical barrier to avoid the passage of bleaching agents into the apical direction and into periodontal tissues, the purpose of this study was to compare the sealing ability of zinc phosphate cement (ZPC) and resin-modified glass ionomer cement (RMGIC) as a cervical barrier when different bleaching agents were used in nonvital bleaching technique.

\section{MATERIALS AND METHODS}

This study was approved by the Research Ethics Committee of the São José dos Campos Institute of Science and Technology, UNESP, São Paulo, Brazil. The study sample was composed of 96 human molars recently extracted which were cleaned with manual instruments and rubber cup with pumice and immersed in saline solution until used. The teeth were radiographically examined and visualized under a stereomicroscope for detection of cracks. 
Coronal access was performed in each tooth crown with a diamond bur under high-speed water spray cooling. After pulpectomy, each root canal was enlarged using $1 \%$ sodium hypochlorite solution (Terapêutica, São José dos Campos, São Paulo, Brazil) and Gates-Glidden burs \# 3 and 4 (GS Brazil Comercial e Importadora Ltda, São Paulo, Brazil) to create root canals of the same size in the cervical and middle third.

The root canals were prepared and filled using the lateral condensation technique with gutta percha points (Dentsply Indústria e Comércio Ltda, Petrópolis, Rio de Janeiro, Brazil) and endodontic sealer (Sealapex-Kerr ${ }^{\circledR}$, CA, USA). The filling material was removed to $3 \mathrm{~mm}$ below the cementoenamel junction by a warm instrument with a silicone stop.

The teeth were divided into two groups with 48 specimens each. The cervical barrier with ZPC (SS White Artigos Dentários Ltda, Rio de Janeiro, RJ, Brazil) was placed and the thickness of $3 \mathrm{~mm}$ was obtained measuring the distance between the entrance of the root canals and the tangent to the occlusal surface with a silicone stop on an endodontic condenser, which was adjusted to the occlusal edge of tooth for reference before and after placement of the material for each tooth.

For the other 48 teeth, the RMGIC was used (Vitremer 3303 Pedo-3M, St Paul, MN, USA). The cavity walls and the floor of the pulp chamber were brushed with primer. After 30 seconds of its application, it was air-dried for 15 seconds, followed by light curing $\left(550 \mathrm{~mW} / \mathrm{cm}^{2}\right)$ for 20 seconds. The powder was mixed with the liquid (2:1) for 45 seconds. The RMGIC was slowly inserted in the pulp chamber supported by a Centrix syringe and light cured for 40 seconds, the finishing gloss was applied on the RMGIC and light cured for 20 seconds, the thickness of $3 \mathrm{~mm}$ was obtained as described previously.

The groups were classified according to the cervical barrier (ZPC or RMGIC) and bleaching agents used:

a. $\mathrm{C} 1$ - control (12 specimens): ZPC + sterile cotton pellet.

b. C2 (12 specimens): ZPC + sodium perborate tetrahydrate (40 mg), (Terapêutica Farmácia de Manipulação, São José dos Campos, SP, Brazil) + distilled water (30 mg).

c. C3 (12 specimens): ZPC + sodium perborate tetrahydrate $(30 \mathrm{mg})+10 \%$ carbamide peroxide $(25 \mathrm{mg})$ (Opalescence, Ultradent Products Inc., South Jordan, UT, USA).

d. C4 (12 specimens): ZPC + sodium perborate tetrahydrate (30 mg) $+35 \%$ carbamide peroxide (25 mg) (Opalescence Quick, Ultradent Products Inc, South Jordan, UT, USA).

e. V1 - control (12 specimens): RMGIC + sterile cotton pellet.

f. V2 (12 specimens): RMGIC + sodium perborate tetrahydrate $(40 \mathrm{mg})+$ distilled water $(30 \mathrm{mg})$. g. V3 (12 specimens): RMGIC + sodium perborate tetrahydrate $(30 \mathrm{mg})+10 \%$ carbamide peroxide $(25 \mathrm{mg})$.

h. V4 (12 specimens): RMGIC + sodium perborate tetrahydrate $(30 \mathrm{mg})+35 \%$ carbamide peroxide $(25 \mathrm{mg})$. Experimental groups received the bleaching agents, which was placed into the access cavity of the tooth, and sealed with a piece of absorbing paper and temporary restorative material (Cimpat, Septodont Brazil LTDA, SP, Brazil).

The teeth were stored in artificial saliva with sodium azide $(0.04 \%)$, and incubated at $37 \pm 1^{\circ} \mathrm{C}$. The bleaching agents were changed after 7 and 14 days. After 21 days, the bleaching agents were removed and the teeth were irrigated with $10 \mathrm{ml}$ saline solution.

Each tooth was externally coated, except for the access opening, with two layers of nail varnish and a thick layer of sticky wax. Two specimens in each group were used as negative (without cervical barrier and complete external coating) and positive controls (without cervical barrier and without external coating).

All the teeth were immersed in rhodamine B 2\% solution at $\mathrm{pH} 7.03$ and then put in a vacuum pump for 1 hour and 30 minutes at $20 \mathrm{~mm} \mathrm{Hg}$. After this period, the specimens were kept in the dye solution and stored at $37 \pm 1^{\circ} \mathrm{C}$ for 48 hours. Then, the teeth were rinsed in tap water for 12 hours and dried naturally. The coating layers were removed and the specimens were sectioned with carborundum disks in lowspeed in the mesiodistal direction.

The evaluation of the maximum extent of dye penetration was performed by a stereomicroscope (MC80DX-ZEISS) at dentin-cervical barrier interface in apical direction. The two sectioned halves were evaluated by two examiners. Eight leakage values were obtained for each specimen, four per examiner. From these data, the highest leakage value for each specimen per examiner was selected and the mean observed for the different groups were submitted to statistical analysis (Kruskal-Wallis, Dunn's and Dunnett's tests with a significance level of 0.05).

\section{RESULTS}

The negative control demonstrated no dye leakage while the positive control demonstrated complete leakage in apical direction, along root filling and inside dentin tubules to the outer root surface.

Data was analyzed using Dunnett's test, comparing experimental groups with control group (Tables 1 and 2). Dunnett's test showed that there was no statistical difference between groups $\mathrm{C} 2, \mathrm{C} 3$ and $\mathrm{C} 4$ when compared to control group $\mathrm{C} 1$, as well as the groups V2, V3 and V4 when compared to control group V1 ( $p>0.05)$. 
Table 1: ZPC cervical barrier. Descriptive statistics analysis for the leakage data $(\mathrm{mm})$, according to the bleaching agents used $(n=10)$

\begin{tabular}{lllll}
\hline Statistics & C1 & C2 & C3 & C4 \\
\hline Mean \pm SD & $2.61 \pm 0.39$ & $2.77 \pm 0.29$ & $2.66 \pm 0.42$ & $2.94 \pm 0.10$ \\
Minimum & 2.00 & 2.30 & 1.95 & 2.70 \\
Median & 2.70 & 2.95 & 2.82 & 3.00 \\
IR $(75-25 \%)^{*}$ & 0.78 & 0.54 & 0.70 & 0.15 \\
Maximum & 3.00 & 3.00 & 3.00 & 3.00 \\
\hline
\end{tabular}

*Interquartile range; C1: Control; C2: Sodium perborate + distilled water; C3: Sodium perborate $+10 \%$ carbamide peroxide; $\mathrm{C} 4$ : Sodium perborate $+35 \%$ carbamide peroxide

\begin{tabular}{|c|c|c|c|c|}
\hline Statistics & V1 & V2 & V3 & V4 \\
\hline Mean \pm SD & $0.70 \pm 0.37$ & $0.50 \pm 0.20$ & $0.55 \pm 0.21$ & $0.53 \pm 0.18$ \\
\hline Minimum & 0.35 & 0.20 & 0.30 & 0.25 \\
\hline Median & 0.55 & 0.50 & 0.50 & 0.50 \\
\hline IR (75-25\%) & 0.39 & 0.29 & 0.34 & 0.33 \\
\hline Maximum & 1.60 & 0.90 & 1.00 & 0.80 \\
\hline
\end{tabular}

*Interquartile range; V1: Control; V2: Sodium perborate + distilled water; V3: Sodium perborate $+10 \%$ carbamide peroxide; $\mathrm{V} 4$ : Sodium perborate $+35 \%$ carbamide peroxide

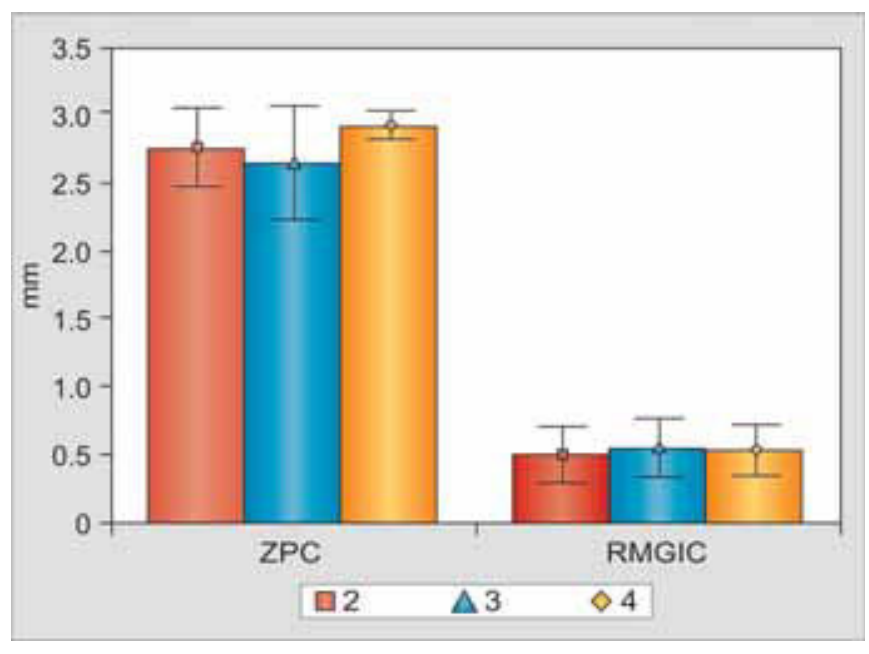

Graph 1: Column bar for the microleakage data (mean \pm standard deviation) according to experimental conditions (2: sodium perborate tetrahydrate + distilled water; 3 : sodium perborate tetrahydrate + $10 \%$ carbamide peroxide; 4 : sodium perborate tetrahydrate $+35 \%$ carbamide peroxide)

Comparing the experimental groups among them can be observed that the bleaching agents presented the same performance when the same cervical barrier was used and the ZPC cervical barrier was different from the RMGIC (Vitremer) cervical barrier (Graph 1).

When the analysis of variance was applied (KruskalWallis nonparametric ANOVA), the hypothesis of equality among the six groups studied was rejected $(\mathrm{kw}=45.974$; $\mathrm{df}=5 ; \mathrm{p}=0.001<0.05)$. The results of the Dunn's multiple comparison test made it possible to present two

\begin{tabular}{llll}
\multicolumn{5}{c}{ Table 3: Homogeneous groups of same performance } \\
according to Kruskal-Wallis and Dunn's tests $(\alpha=5 \%)$
\end{tabular}

*Same letters indicate no significant statistical difference

homogeneous groups* of same performance for marginal leakage (Table 3).

The RMGIC (Vitremer) cervical barrier provided better sealing than the ZPC cervical barrier, regardless of the association of bleaching agents used (Table 3 ).

\section{DISCUSSION}

Walking bleaching is a technique commonly used in discolored endodontically treated anterior teeth. ${ }^{12}$ Bleaching agents used in this technique includes hydrogen peroxide and sodium perborate. Although these agents are effective in lightening tooth color, their use has been associated with some problems, such as external cervical root resorption. ${ }^{12}$

Some studies support the hypothesis that hydrogen peroxide may cause external cervical root resorption by 
diffusion from the pulp chamber through dentinal tubules to the outer root surface. Penetration of hydrogen peroxide toward the periodontal ligament may cause localized damage and initiate an inflammatory reaction resulting in bone and root resorption. ${ }^{6}$ Moreover, some studies have shown that the $\mathrm{pH}$ at the root surface is reduced by intracoronal placement of bleaching agents. ${ }^{13}$ However, the exact mechanism responsible for external cervical root resorption in bleached teeth has not been adequately explained. ${ }^{12,14}$

To prevent the penetration of hydrogen peroxide along the filled root canal of the apical region and the inside the dentin tubules, from the canal wall to the outer root surface, it has been recommended to place a protective base over the root canal filling, preferably at the level of the vestibular cementoenamel junction, with a minimum thickness of $2 \mathrm{~mm} .{ }^{15}$ In our study, a $3 \mathrm{~mm}$ thick cervical barrier was used up to the cementoenamel junction level.

In view of large number of leakage studies published, it seems generally accepted that evaluation of the leakage of particles or solutions between a root filling and the root canal wall is a suitable method to ascertain whether a root canal filling fulfills its purpose. ${ }^{16}$ The methods which use dye tracers are inexpensive and easy to perform. ${ }^{12}$ The use of rhodamine B as a tracer in conjunction with a confocal microscope has several advantages: minimal specimen preparation, no need to desiccate the specimen, high resolution imaging and direct viewing and examination of samples below the surface using immersion objectives. ${ }^{17}$ In addition, dye studies are the easiest method to screen new restorative filling materials. ${ }^{18}$ The rhodamine B was used in this study as a marker due to its characteristics, showing the leakage pattern and extent of dye penetration is easy to detect even in the dentinal tubules.

The intracoronal bleaching of nonvital teeth is frequently performed with a mixture of sodium perborate and hydrogen peroxide. The sodium perborate, when in contact with water decomposes in hydrogen peroxide and releases active oxygen which starts the bleaching process. ${ }^{19}$ The amount of hydrogen peroxide leakage depends on the type of sodium perborate used. Then, more leakage is reported with the use of sodium perborate monohydrate or tetrahydrate combined with hydrogen peroxide than with sodium perborate trihydrate combined with hydrogen peroxide or sodium perborate tetrahydrate combined with water. Thus, the use of sodium perborate tetrahydrate mixed with water is recommended as a bleaching agent to reduce the potential risk of cervical root resorption. ${ }^{6,19}$ In this study, the some experimental groups received a mixture of carbamide peroxide and sodium perborate. Gökay et $\mathrm{al}^{20}$ compared radicular peroxide diffusion from different concentrations of carbamide peroxide bleaching gels (10, 17 and 35\%) and a mixture of $30 \%$ hydrogen peroxide and sodium perborate and concluded that peroxide penetration of carbamide peroxide gels was significantly lower than the mixture and suggested that carbamide peroxide gels might promote less risk of postbleaching external cervical root resorption.

In the present study, it was observed that the use of a cervical barrier over the root canal filling before the intracoronal bleaching did not completely prevent the dye leakage through the dentin-cervical barrier interface. These results agree with the other authors ${ }^{11,12,19,21}$ using different materials for the cervical barrier.

The leakage means observed for the dentin-cervical barrier interface suggest that the use of RMGIC (Vitremer) over the root canal filling, when submitted to internal bleaching with the bleaching agents tested was able to reduce the linear dye leakage in apical direction. The maximum leakage was $1.60 \mathrm{~mm}$. This must have occurred due the adhesion of dentin adhesive used, which resulted in great penetration in the dentin tubules and resistance to microleakage. Liebenberg ${ }^{22}$ attributed the same result in his study due to its precise bubble-free application using a Centrix syringe.

Studies found in literature indicate controversial results concerning the efficiency and thickness of materials used as cervical barrier. In this study, it was observed that the use of a cervical barrier did not completely prevent the dye leakage in apical direction. These results agree with other authors using different materials for the same purpose., ${ }^{4,23-26}$

Brito-Junior et $\mathrm{al}^{21}$ when compared some materials used as cervical barrier in nonvital bleaching, concluded that WMTA presented higher sealing ability than Vidrion R (a conventional glass ionomer) when teeth were submitted to bleaching with $30 \%$ hydrogen peroxide associated to sodium perborate for 24 hours.

The bleaching agents can pass from the canal to the external environment ${ }^{27}$ and diffuse through the root dentin specially in the presence of defects in the cement. ${ }^{5,19}$ Therefore, an effective cervical barrier against the penetration of bleaching agents in apical direction and to the periodontal tissues is extremely important. To keep the levels of extraradicular diffusion of hydrogen peroxide below the safety limit, $\mathrm{Lim}^{28}$ considered imperative that an effective intermediate base cement of at least $2 \mathrm{~mm}$ should be placed at the level of the buccal cementoenamel junction over the root-filling prior to bleaching.

In our study, inside the dentinal tubules, from the canals wall to the outer root surface, the cervical barrier did not prevent the leakage in most specimens. This fact is concerning for teeth with cementum defects, where the intracoronal bleaching technique might cause external cervical root resorption. ${ }^{19}$ 
Vosoughhosseini et $\mathrm{al}^{12}$ recommended that a protective barrier should be used over the canal filling to prevent leakage of bleaching agents, because there is some evidence that the $\mathrm{pH}$ at the root surface is reduced by intracoronal placement of bleaching pastes, which is known to enhance osteoclastic activity. In their study, it was demonstrated that glass ionomer (Fuji glass-ionomer cement, II LC, Japan) and white mineral trioxide aggregate (WMTA, Tooth-colored Formula, Dentsply, Tulsa Dental, USA), when used as a cervical barrier ( $3 \mathrm{~mm}$ ), exhibited minimal leakage which was not significantly different from the negative controls. The three bleaching agents were $30 \%$ hydrogen peroxide, sodium perborate mixed with $30 \%$ hydrogen peroxide and sodium perborate mixed with distilled water. These authors showed that in spite of negative effects of bleaching agents on restorative materials, these effects could not alter microleakage properties of GIC and WMTA tested.

The use of RMGIC containing positive characteristics, such as structure dental adherence, be light-curable, resistant to dissolution by the bleaching agent, presenting esthetic coloration and do not staining the dental structure as time goes by. These features satisfied some of the requirements proposed by Macisaac and Hoen, ${ }^{29}$ for the selection of an ideal cervical barrier. A cervical barrier with RMGIC might reduce apical leakage of the bleaching agents, but such barrier might not prevent penetration of the bleaching agents into the dentin tubules from the canal wall toward the outer root surface. Thus, the deficient cervical sealing and high concentrations of bleaching agents should be avoided, as this can increase the risk of cervical root resorption. ${ }^{14}$

\section{CONCLUSION}

Considering the results obtained, it can be concluded that the bleaching agents used in this study showed similar performance when tested for the same barrier and the RMGIC (Vitremer) cervical barrier provided better sealing than the ZPC cervical barrier, regardless of the association of bleaching agents used.

\section{ACKNOWLEDGMENTS}

This study was supported by CAPES and FUNDUNESP (Fundação para o Desenvolvimento da UNESP). The authors thank Ivan Balducci for the statistical analysis of the results.

\section{REFERENCES}

1. Harrington GW, Natkin E. External resorption associated with bleaching of pulpless teeth. J Endod 1979;5:344-348.

2. Friedman S, Rotstein I, Libfeld H, Stabholz A, Heling I. Incidence of external root resorption and esthetic results in 58 bleached pulpless teeth. Endod Dent Traumatol 1988;4:23-26.
3. Holmstrup G, Palm AM, Lambjerg-Hansen H. Bleaching of discoloured root-filled teeth. Endod Dent Traumatol 1988;4: 197-201.

4. Ho S, Goerig AC. An in vitro comparison of different bleaching agents in the discolored tooth. J Endod 1989;15:106-111.

5. Rotstein I, Torek Y, Misgav R. Effect of cementum defects on radicular penetration of $30 \% \mathrm{H}_{2} \mathrm{O}_{2}$ during intracoronal bleaching. J Endod 1991;17:436-441.

6. Weiger R, Kuhn A, Lost C. Radicular penetration of hydrogen peroxide during intracoronal bleaching with various forms of sodium perborate. Int Endod J 1994;27:313-337.

7. Ari H, Ungor M. In vitro comparison of different types of sodium perborate used for intracoronal bleaching of discoloured teeth. Int Endod J 2002;35:433-436.

8. Vachon C, Vanek P, Friedman S. Internal bleaching with $10 \%$ carbamide peroxide in vitro. Pract Period Aesthet Dent 1998;10:1145-1148,1150, 1152.

9. Perrine GA, Reichl RB, Baisden MK, Hondrum SO. Comparison of $10 \%$ carbamide and sodium perborate for intracoronal bleaching. Gen Dent 2000;48:264-270.

10. Lado EA, Stanley HR, Weisman MI. Cervical resorption in bleached teeth. Oral Surg Oral Med Oral Pathol 1983;55:78-80.

11. Heller D, Skriber J, Lin LM. Effect of intracoronal bleaching on external cervical root resorption. J Endod 1992;18:145-148.

12. Vosoughhosseini S, Lotfi M, Shahmoradi K, Saghiri MA, Zand V, Mehdipour M, Ranjkesh B, Mokhtari H, Salemmilani A, Doosti S. Microleakage comparison of glass-ionomer and white mineral trioxide aggregate used as a coronal barrier in nonvital bleaching. Med Oral Patol Oral Cir Bucal 2011 Nov 1;16(7):e1017-e1021.

13. Patel S, Kanagasingam S, Pitt Ford T. External cervical resorption: a review. J Endod 2009;35:616-625.

14. Sá PM, Jeronymo RDI, Yui KCK, Silva EG, Huhtala MFRL, Torres CRG, Gomes APM. Effect of calcium hydroxide on $\mathrm{pH}$ changes of the external medium after intracoronal bleaching. J Contemp Dent Pract 2011;12(3):158-163.

15. Smith J, Montgomery S. Cervical canal leakage after internal bleaching procedures. J Endod 1992;18:476-481.

16. Wu MK, Wesselink PR. Endodontic leakage studies reconsidered. Part I. Methodology, application an relevance. Int Endod J 1993;26:37-43.

17. Chong BS, PittFord TR, Watson TF. The adaptation and sealing ability of light-cured glass ionomer retrograde fillings. Int Endod J 1991;24:223-232.

18. Torabinejad M, Watson TF, Pitt Ford TR. Sealing ability of a mineral trioxide aggregate when used as a root end filling material. J Endod 1993;16:591-595.

19. Oliveira LD, Carvalho CAT, Hilgert E, Bondioli IR, Araújo MAM, Valera MC. Sealing of the cervical base in intracoronal bleaching. Dental Traumatology 2003;19:309-313.

20. Gökay O, Ziraman F, Çali Asal A, Saka OM. Radicular peroxide penetration from carbamide peroxide gels during intracoronal bleaching. Int Endod J 2008;41:556-560.

21. Brito-Júnior M, Faria-e-Silva AL, Fonseca B, Camilo CC. Sealing ability of MTA used as cervical barrier in intracoronal bleaching. Acta Odontol Latinoam 2009;22(2):118-122.

22. Liebenberg WH. Intracoronal lightening of discolored pulpless teeth: a modified walking bleach technique. Quintessence Int 1997;28:771-777.

23. Warren MA, Wong M, Ingram III TA. An in vitro comparison of bleaching agents on the crowns and roots of discolored teeth. J Endod 1990;16:463-467. 
24. Mcinerney ST, Zillich R. Evaluation of internal sealing ability of three materials. J Endod 1992;18:376-378.

25. Brighton DM, Harrington GW, Nicholls JI. Intracoronal isolating barriers as they relate to bleaching. J Endod 1994;20:228-232.

26. Zaia AA, Nakagawa R, De Quadros I, Gomes BP, Ferraz CC, Teixeira FB, Souza-Filho FJ. An in vitro evaluation of four materials as barriers to coronal microleakage in root-filled teeth. Int Endod J 2002;35:729-734.

27. Fuss Z, Szajkis S, Tagger M. Tubular permeability to calcium hydroxide and to bleaching agents. J Endod 1989;15:362-364.

28. Lim KC. Considerations in intracoronal bleaching. Aust Endod J 2004;30(2):69-73.

29. Macisaac AM, Hoen MM. Intracoronal bleaching concerns and considerations. J Can Dent Assoc 1994;60:57-64.

\section{ABOUT THE AUTHORS}

\section{Karen Cristina Kazue Yui}

Assistant Professor, Department of Restorative Dentistry, São José dos Campos Institute of Science and Technology, UNESP, São Paulo State University, São Paulo, Brazil

Correspondence Address: Avenida Engenheiro Francisco José Longo, 777, Jardim São Dimas, São José dos Campos, São Paulo, Brazil, CEP: 12245-000, Phone:+55 (12)3947 9048, e-mail: karenyui@fosjc.unesp.br

\section{Maria Filomena Rocha Lima Huhtala}

Assistant Professor, Department of Restorative Dentistry, São José dos Campos Institute of Science and Technology, UNESP, São Paulo State University, São Paulo, Brazil

\section{Eduardo Galera da Silva}

Assistant Professor, Department of Social and Pediatric Dentistry, São José dos Campos Institute of Science and Technology, UNESP, São Paulo State University, São Paulo, Brazil

\section{Carolina Judica Ramos}

Assistant Professor, Department of Social and Pediatric Dentistry, São José dos Campos Institute of Science and Technology, UNESP, São Paulo State University, São Paulo, Brazil

\section{Carlos Rocha Gomes Torres}

Associate Professor, Department of Restorative Dentistry, São José dos Campos Institute of Science and Technology, UNESP, São Paulo State University, São Paulo, Brazil

\section{Sérgio Eduardo de Paiva Gonçalves}

Associate Professor, Department of Restorative Dentistry, São José dos Campos Institute of Science and Technology, UNESP, São Paulo State University, São Paulo, Brazil

\section{Ana Paula Martins Gomes}

Associate Professor, Department of Restorative Dentistry, São José dos Campos Institute of Science and Technology, UNESP, São Paulo State University, São Paulo, Brazil 